\title{
KOMUNIKASI KESEHATAN PADA PROGRAM PEMANFAATAN SARANA DAN PRASARANA DESA RAWABOGO UNTUK KEBUTUHAN MASYARAKAT MENUJU KEHIDUPAN YANG SEHAT
}

\author{
Krisna Aditya \\ Universitas Kebangsaan, Fakultas Ilmu Sosial dan Sastra, Ilmu Komunikasi \\ ${ }^{1}$ korespondensi : krisnaaditya.ukri@ protonmail.com
}

\begin{abstract}
ABSTRAK
Komunikasi berperan penting dalam penyampaian informasi utamanya komunikasi kesehatan. Komunikasi kesehatan digunakan sebagai upaya pengoptimalan untuk kebutuhan masyarakat menuju kehidupan yang sehat. Desa Rawabogo Ciwidey, Kabupaten Bandung termasuk destinasi favorite tujuan wisata di provinsi Jawa Barat. Permasalahannya adalah kehidupan yang sehat masyarakat Desa Rawabogo belum terlaksana secara optimal, hal tersebut bisa dilihat dari banyaknya permasalahan yang timbul mengenai kelayakan hidup sehat, minimnya protol kesehatan, pemanfaatan sarana dan prasarana kesehatan di desa Rawabogo. Peneliti memilih praktek penerapan komunikasi kesehatan yang diselenggarakan di Desa Rawabogo, Kabupaten Bandung. Pencapaian kesehatan optimal menjadi salah satu aspek yang dituju komunikasi kesehatan. Di mana kajian jurnal ini memfokuskan pada penggunaan efektifitas komunikasi di bidang kesehatan yang menginformasikan dan mempengaruhi keputusan individu dan masyarakat dalam mempertinggi kehidupan yang sehat. Dengan menggunakan pendekatan wawancara dan diskusi, kelompok Pengabdian Kepada Masyarakat Universitas Kebangsaan UKRI bekerja sama dengan Universitas Sangga Buana USB YPKP mengedukasi dan mengkomunikasikan pentingnya komunikasi di bidang kesehatan di desa tersebut. Obyek penelitiannya adalah praktek penerapan komunikasi dibidang kesehatan untuk kebutuhan masyarakat Rawabogo, Kabupaten Bandung, menuju kehidupan yang sehat. Hasil penelitian menunjukkan bahwa penerapan komunikasi kesehatan efektif merubah perilaku masyarakat Desa Rawabogo menuju kehidupan yang sehat.
\end{abstract}

Kata Kunci: Komunikasi Kesehatan, Pengabdian Masyarakat, Hidup Sehat

\begin{abstract}
Communication plays an important role in delivering information, especially health communication. Health communication is used as an effort to optimize society's needs towards a healthy life. Rawabogo Ciwidey Village, Bandung Regency is one of the favorite tourist destinations in West Java province. The problem is that the healthy life of the people of Rawabogo Village has not been implemented optimally, this can be seen from the many problems that arise regarding the feasibility of living a healthy life, the lack of health protocols, utilization of health facilities and infrastructure in Rawabogo Village. Researchers chose the practice of implementing health communication which was held in Rawabog Village, Bandung Regency. The achievement of optimal health is one of the aspects aimed at health communication. Where the study of this journal focuses on the use of effective communication in the health sector that informs and influences individual and community decisions in enhancing a healthy life. By using an interview and discussion approach, the UKRI Kebangsaan University Community Service group in collaboration with Sangga Buana USB YPKP University educates and communication in the health sector in the village. The object of his research is the practice of implementing communication in the health sector for the needs of the people of Rawabogo, Bandung Regency, towards a healthy life. The results showed that the implementation of health communication effectively changed the behavior of the people or Rawabogo Village towards a health life.
\end{abstract}

Keywords: Health Communication, Community Service, Healthy living

\section{PENDAHULUAN}

Selama dasawarsa terakhir di tengah wabah covid19 saat ini, banyak kalangan akademisi, dosen dan peneliti melakukan riset ilmiah tentang komunikasi kesehatan bersifat kulutural di Indonesia. Para peneliti tidak jarang 
berkolaborasi dengan peneliti dari universitas lain di dalam dan di luar negeri.

Desa Rawabogo Ciwidey, Kabupaten Bandung merupakan destinasi favorit wisata di provinsi Jawa Barat. Namun demikian, kehidupan yang sehat belum di dukung dengan pengetahuan kesehatan, bimbingan dan pengarahan untuk memaksimalkan sarana dan prasarana pada bidang kesehatan.

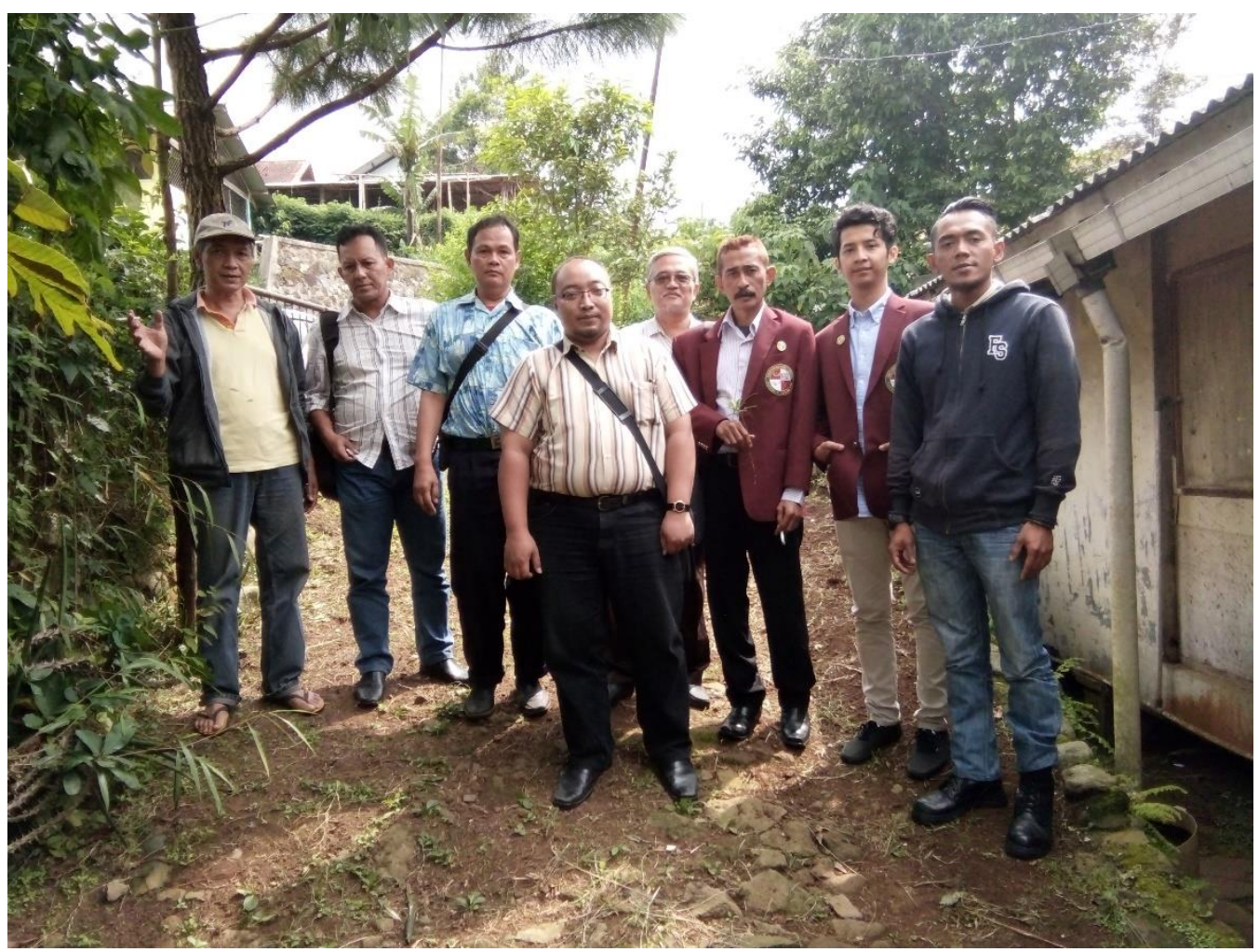

Gambar 1: Tim Pengabdian kepada Masyarakat Bersama (PKMB) USB - UK

Oleh sebab itu, dosen Universitas Kebangsaan (UKRI) bersama dosen Universitas Sangga Buana (USB YPKP) berkolaborasi melakukan kegiatan Pengabdian kepada Masyarakat (PKM) di desa tersebut, dengan tujuan dapat membantu masyarakat untuk memanfaatkan sarana dan prasarana dibidang kesehatan untuk kebutuhan Desa Rawabogo menuju kehidupan yang sehat, dengan harapan akan berdampak positif juga kepada masyarakat desa itu sendiri. Salah satu upaya menuju kehidupan yang sehat adalah dengan cara melakukan komunikasi di bidang kesehatan kepada masyarakat di Desa Rawabogo. Komunikasi kesehatan merupakan penggunaan strategi komunikasi untuk menyebarluaskan informasi kesehatan yang memengaruhi, dan memotivasi individu, institusi dan komunitas untuk membuat keputusan yang erat hubungan dengan bidang kesehatan [1]. Dengan demikian, komunikasi kesehatan berlangsung setiap tingkatan, baik individu, kelompok , organisasi, komunitas, masyarakat dan media. Komunikasi kesehatan merupakan pendekatan multifaset dan multidisplin untuk mencapai berbagai kelompok sasaran dan menyampaikan informasi terkait kesehatan dengan tujuan memengaruhi, melibatkan, mendukung individu, masyarakat, tenaga medis, kelompok tertentu, pengambil kebijakan dan masyarakat 
untuk menjadi penggagas, mengenalkan, menerima atau memelihara suatu perilaku, praktik atau kebijakan yang pada akhirnya akan meningkatkan dampak terhadap kesehatan.

Mensadari pentingnya komunikasi kesehatan, maka peneleliti tergerak untuk melakukan penelitian yang berkaitan dengan penerapan komunikasi kesehatan untuk kebutuhan masyarakat menuju hidup kehidupan yang sehat pada masyarakat Desa Rawabogo, Kabupaten Bandung Provinsi Jawa Barat.

Pertanyaan terkait dengan komunikasi kesehatan dalam kegiatan PKM pada penelitian ini adalah: "Bagaimanakah penerapan komunikasi di bidang kesehatan di Desa Rawabogo?". Komunikasi di bidang kesehatan memberi arahan, advis, atau petunjuk-petunjuk yang dibutuhkan masyarakat ketika adaptasi kebiasaan untuk hidup bersih dan sehat yang pada praktik pelakasanaanya akan terus berkesinambungan.

Dari uraian diatas, komunikasi kesehatan dibutuhkan dengan mengedukasi masyarakat seputar istilah-istilah medis dan menjelaskan berbagai persoalan yang erat hubungannya dengan kehidupan yang sehat.

Kesiapan dan kelayakan sarana dan prasarana mendorong masyarakat di Desa Rawabogo memanfaatkan fasilitas yang telah dicanangkan dan di program bersama kelompok PKM Universitas Kebangsaan dan Univeritas Sangga Buana. Untuk itulah, kolaborasi dua universitas perguruan tingggi di Bandung ini juga berkontribusi bagaimana mendisiplinkan masyarakat di Desa Rawabogo untuk selalu menjaga kebersihan dan protocol kesehatan.
Hidup sehat tentunya dibarengi dengan perilaku kesehatan, banyak ragamnya untuk menggambarkan perilaku kesehatan contohnya tidak membuang puntung rokok sembarangan, tidak menggunaan narkoba dan sejenisnya, pada pembahasan perilaku yang dimaksud untuk masyarakat Desa Rawabogo, difokuskan pada kepatuhan adaptasi hidup bersih.

Perilaku kesehatan sering dikaji sebagai perilaku tingkat individu, tetapi dapat diukur dan ditingkatkan pada kelompok, atau populasi. Perilaku kesehatan bersifat dinamis, polanya bervariasi sepanjang masa, antar kelompok, antar pengaturan, dan dari waktu ke waktu.

Kemajuan konseptual dan metodologis dalam mendefinisikan perilaku kesehatan menekankan pada pengukuran integrative dan dinamis. Kemajuan teroritis penting dalam decade terakhir adalah konsep "gaya hidup sehat". Kebijakan yang menargetkan perilaku kesehatan cenderung berfokus pada satu perilaku, seringkali menemukan bahwa perilaku tesebut tahan terhadap perubahan. Pendekatan gaya hidup sehat memandang perilaku yang terjadi dan saling mempengaruhi, berkembang dari identitas yang mengakar yang timbul dari keanggotaan dalam kelompok sosial. Jadi, gaya hidup kesehatan diberlakukan pada tingkat individu tetapi dibentuk oleh tingkat makro dan mikro. Memahami interaksi antara perilaku kesehatan dipandang sebagai dasar untuk berhasil mengubah perilaku tersebut.

Perilaku kesehatan juga dikaitakan dengan banyak hasil kesehatan dan kesejahteraan di tingkat individu dan populasi. Penulis menarik 
minat dalam ulasan ini pada penerapan pendekatan "determinan sosial' yang sekarang diterapkan secara luas pada bidang kesehatan dan spesifik perilaku kesehatan.

Di antara banyak teori dan model perilaku kesehatan, yang relevan pada penelitian program pemanfaatan sarana dan prasarana Desa Rawabogo untuk kebutuhan masyarakat menuju kehidupan yang sehat, kami gunakan

Teori pemahaman sosial (social learning theory). Social learning theory berbicara pada relasi segitiga antara "orang" (menyangkut proses-proses kognitif), behaviors dan lingkungan dalam suatu proses "deterministik resiprokal" ("kausalitas resiprokal") [2]. Lingkungan menentukan atau menyebabkan terjadi perilaku kebanyakan, maka seorang individu menggunakan proses kognitifnya untuk menginterpresentasikan lingkungan maupun kebiasaan yang dijalankannya, serta memberikan reaksi dengan cara mengubah lingkungan dan menerima hasil perilaku yang lebih baik. Oleh model-model kognitif, atau model-model yang berorientasi pada pembuatan keputusan logika, dengan behaviors theory [2].

Penerapan komunikasi kesehatan yang tepat dinilai mampu memberikan kontribusi menuju kehidupan yang sehat di Desa Rawabogo, Kabupaten Bandung. Dengan melaksanakan program-program komunikasi kesehatan yang efektif masyarakat bisa mendapatkan informasi penting yang perlu mereka ketahui seputar hidup sehat.

Berdasarkan uraian di atas, maka perlu diadakan penelitian untuk melihat penerapan komunikasi kesehatan serta perannya dalam meningkatkan pengetahuan sikap dan perilaku warga masyarakat di Desa Rawabogo, Ciwidey, Kabupaten Bandung dalam upaya pemanfaatan sarana dan prasaran menuju kehidupan yang sehat. Untuk tujuan tersebut maka penelitian ini akan menggunakan metode melakukan kunjungan, wawancara dan diskusi guna mengamati penerapan komunikasi kesehatan yang dilakukan dalam upaya penerapan hidup sehat.

\section{METODE}

Kajian dalam penelitian ini adalah masyarakat Desa Rawabogo dimana setiap kelompok kemudian melaksanakan tugasnya dengan menggunakan dua cara/metode, yaitu melakukan kunjungan kepada masyarakat dan mewawancarainya, serta melakukan presentasi dan diskusi langsung dengan masyarakat beserta. Kegiatan komunikasi kesehatan yang dilakukan oleh dosen yang bertugas memberikan respon terhadap kebiasan warga dalam upaya penerapan hidup yang lebih sehat. Kunjungan, wawancara dan diskusi kepada masyarakat bertujuan agar para dosen bisa membaca masalah apa yang menjadi keluhan oleh masyarakat berkaitan dengan saran dan prasarna bagi kebutuhan masyarakat untuk hidup sehat, untuk kemudian dilakukan analisa mengatasi permasalahan tersebut. Setelah analisa permasalahan didapatkan, para dosen kemudian mempresentasikan solusi untuk permasalahan sarana dan prasarana dalam bentuk penyuluhan dan membuka ruang diskusi untuk membahasnya lebih mendalam jika 
permasalahan dirasa belum mendapat titik temu

oleh masyarakat desa.

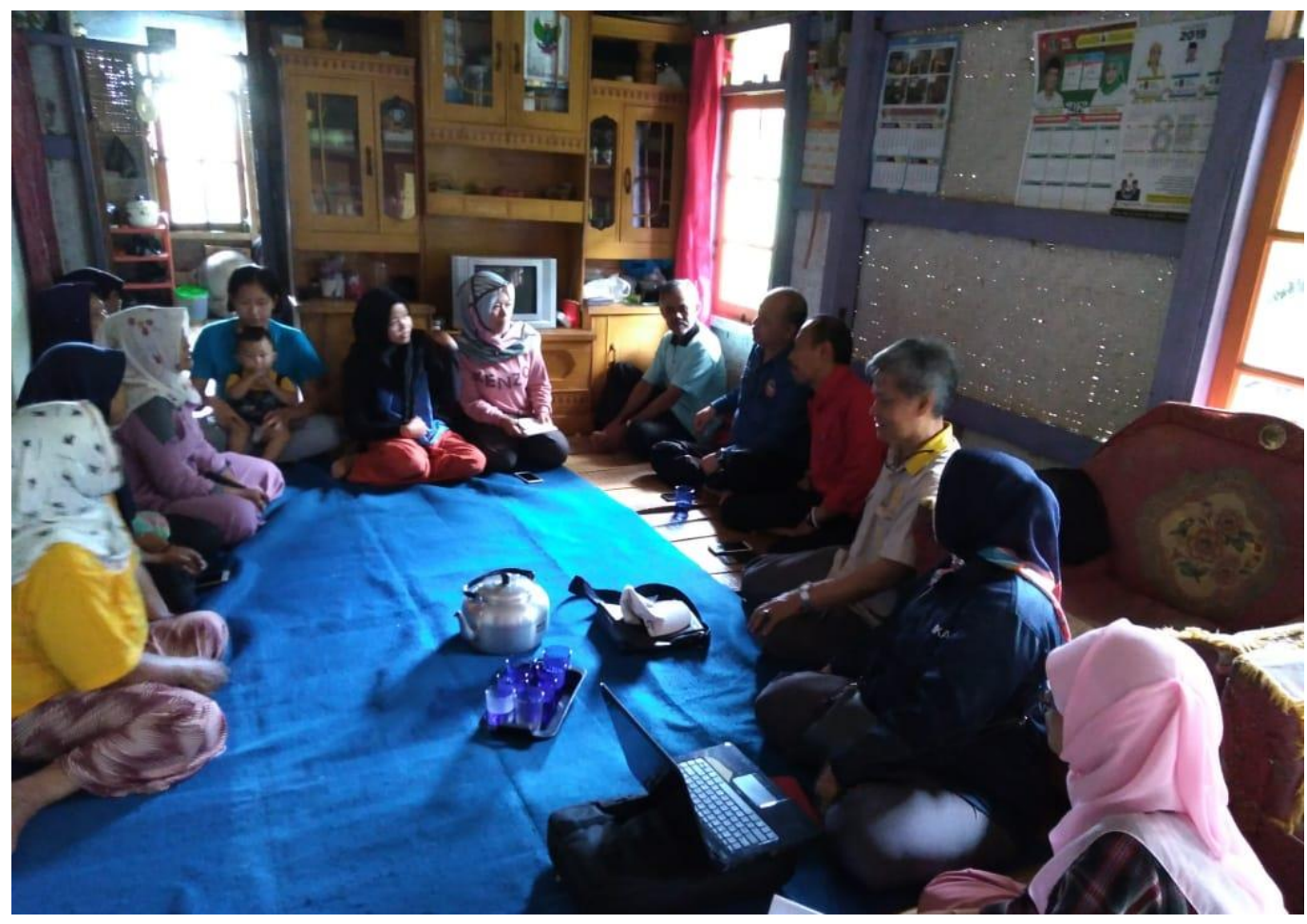

Gambar 2: Proses Diskusi dengan Masyarakat

Penyuluhan diartikan sebagai hubungan timbal balik antara dua pihak untuk mencapai pengertian tentang peranan dalam hubungan dengan masalah-masalah yang dihadapi pada waktu yang akan datang. Dari pengertian tersebut, terlihat bahwa sasaran penyuluhan adalah suatu pihak yang mempunyai masalah tentang suatu hal. Kemudian, setelah mengikuti penyuluhan, diharapkan pihak tersebut memperoleh konsep diri dan kepercayaan diri dalam memperbaiki keadaan saat ini dan masa yang akan datang.

Penelitian ini disertai teori maupun literatur pakar komunikasi, dan kesehatan masyarakat yang semuanya diperoleh melalui berbagai literatur, baik itu buku-buku, jurnal-jurnal, maupun artikel-artikel.

\section{HASIL DAN PEMBAHASAN}

Pada bagian ini analisis terhadap berbagai hal yang terkait dalam pelaksanaan PKM seperti permasalahan, pola-pola, serta kecenderungan yang terjadi dalam penerapan komunikasi kesehatan untuk hidup sehat di Desa Rawabogo akan diuraikan.

Pelaksanaan PKM di Desa Rawabogo kegiatannya menghasilkan point-point, antara lain :

1) Memberikan input pengembangan pemanfaatan sarana dan prasarana Desa Rawabogo menuju kehidupan yang sehat

2) Memotifasi adaptasi hidup yang bersih bagi individu dan masyarakat Desa Rawabogo

3) Komunikasi informasi kesehatan menyalurkan pesan-pesan public health dan health behavior. 
4) Dengan komunikasi kesehatan memberi arahan, advis atau petunjuk-petunjuk yang dibutuhkan masyarakat Desa Rawabogo.

5) Memberikan tips sehat agar disiplin, membuat dan memiliki perencanaan utamanya pada bidang kesehatan

Untuk menekan program pemanfaatan sarana dan prasaran menuju hidup sehat dan mecegah dampak negatif yang harus dilakukan pertamatama adalah menyebarkan informasi penting mengenai manfaat hidup sehat ke seluruh warga masyarakat. Pengetahuan warga mengenai kesehatan akan memegaruhi sikap dan perilakunya [3]. Input komunikasi kesehatan sebagai berikut :

1) Memberikan sosialisasi pemanfaatan dan pentingnya sarana dan prasarana di Desa Rawabogo untuk kebutuhan kesehatan masyarakat.

2) Memonitor kondisi dan lokasi masyarakat Desa Rawabogo dan menberikan penjelasan tentang edukasi Komunikasi dibidang Kesehatan

3) Memberikan penyuluhan tentang program pengembangan pemanfaatan sarana dan prasarana kehidupan yang sehat untuk masyarakat

4) Memberi pengarahan tentang usaha-usaha dalam mewujudkan kehidupan yang sehat.

5) Memberi input dan pembinaan motifasi hidup sehat, olah raga dan pola aktifitas sehat lain yang dilakukan individu dalam kehidupan sehari-hari.

Penerapan komunikasi kesehatan yang dilakukan PKMB Universitas Kebangsaan dan USB Sangga Buana untuk program pengembangan pemanfaatan sarana dan prasarana menuju kehidupan yang sehat juga sesuai dengan behaviors theory .

Selain itu Komunikasi di bidang Kesehatan harus memiliki daya eksplanatori . Penyampaian pesan - pesan kesehatan dengan istilah asing harus dijabarkan secara baik dan benar. Hal tersebut disebabkan karena banyak warga Desa Rawabogo yang masih menggunakan bahasa sunda dan tidak paham istilah medis. Untuk mengatasi hambatan ini, petugas dan dosen berintraksi dengan masyarakat dalam melakukan proses sosialisasi dan edukasi lebih banyak menggunakan bahasa Indonesia yang mudah dipahami warga Desa Rawabogo.

Hal ini bertujuan agar masyarakat lebih mudah menerima materi yang diberikan. petugas juga menggunakan istilah-istilah yang mudah dipahami oleh masyarakat. Penggunaan istilah kedokteran dan medis terkadang justru menjadi penghambat proses pemahaman karena masyarakat desa sebagian cenderung sulit menyebut dan mengingat kembali istilah-istilah tersebut [4].

Respon positif di tunjukkan masyarakat Desa Rawabogo selama berlangsungnya wawancara dan pemaparan materi oleh kelompok PKMB Universitas Kebangsaan dan USB Sangga Buana, hal tersebut ditandai dengan bersemangat dan antusias yang tinggi masyarakat Desa Rawabogo menuju kehidupan yang sehat. Dan secara keseluruhan selama pelaksanaan kegiatan PKM berjalan dengan lancar. 


\section{KESIMPULAN DAN SARAN}

\section{Kesimpulan}

Dari hasil observasi dan analisis penelitian mengenai penerapan komunikasi kesehatan menuju kehidupan sehat di Desa Rawabogo dapat ditarik beberapa kesimpulan sebagai berikut:

1) Upaya untuk pengembangan pemanfaatan sarana dan prasarana Desa Rawabogo menuju kehidupan yang sehat adalah dengan melaksanakan program di bidang kesehatan

2) Menuju kehidupan yang sehat, Desa Rawabogo sehat, Jawa Barat Sehat, maka sinergi langkah seluruh pihak harus terjadi, kuncinya ada di kemampuan komunikasi.

3) Efektifitas Komunikasi Kesehatan mempengaruhi individu dan masyarakat menuju kehidupan yang sehat.

\section{Saran}

1) Adanya pembinaan berkesinambungan dan pelatihan tenaga kesehatan yang juga berperan sebagai komunikator.
2) Himbauan informatif melalui media yang edukatif tentang pentingnya protocol kesehatan serta Perilaku Hidup Bersih dan Sehat.

3) Dengan era baru kini, berbagai inovasi menanfaatkan kecanggihan teknologi sangat dimungkinkan. Oleh karena itu, strategi komunikasi kesahatan pun bisa memanfaatkan teknologi tersebut.

\section{DAFTAR PUSTAKA}

[1] Kusumawati, Dyah, et al. (2015). Komunikasi dan Isu Publik. Yogyakarta: Buku Litera.

[2] Liliweri, Alo. (2009). Dasar-dasar Komunikasi Kesehatan. Yogyakarta: Pustaka Pelajar.

[3] Atmonobudi, Billy K. Sarwono. (2005). Panduan Lapangan Merancang Strategi Komunikasi Kesehatan. Jakarta: Program STARH.

[4] Endrawati, Endah. "Penerapan Komunikasi Kesehatan Untuk Pencegahan Penyakit LeptospirosisPada Masyarakat Desa Sumberagung, Kecamatan Moyudan, Sleman, Yogyakarta" . Jurnal Komunikasi, Vol 7 No 1, Juli 2015. Hal 1-25 